\title{
Correlation between stereoacuity and induced astigmatism: a prospective study
}

\author{
Gagal B. D. ${ }^{1}$, Parekh K. ${ }^{2}$ \\ ${ }^{1}$ Dr. Bhavna Dhanji Gagal, Assistant Professor, ${ }^{2}$ Dr. Kavita Parekh, Associate Professor; both authors are affiliated with \\ Department of Ophthalmology, Gujarat Adani Institute of Medical Science, Bhuj, Kutch, Gujarat, India.
}

Corresponding Author: Dr. Kavita Parekh, Department of Ophthalmology, Gujarat Adani Institute of Medical Science, Bhuj, Kutch, Gujarat, India. E-mail: drpiyushpujara@gmail.com

\begin{abstract}
Background and Aim: Stereopsis represents the highest grade of Binocular Single Vision wherein two dissimilar images of the same object are formed, simultaneously, at the maculae of the two eyes, and these images are then processed in the visual cortex to produce a single fused image, whose location in space can be perceived. Material and Methods: Present Randomized, Prospective, Comparative, study was performed at Department of Ophthalmology Bharati Hospital \& Research Centre, Pune. Two thousand subjects were divided into two groups, they were divided into 2 groups using randomized table. Group 1 was subjected to binocular induced astigmatism. Group 2 was subjected to monocular induced astigmatism. Binocular Induced Astigmatism was induced in two groups, (500 participants in each group) either Myopic Astigmatism or Hypermetropic Astigmatism, similarly Monocular was further subdivided in to two groups (500 participants in each group): Myopic Astigmatism and Hypermetropic Astigmatism. Results: With both +1 Dcyl \& +2 Dcyl binocular induced myopic astigmatism, stereoacuity was affected maximum at $45^{\circ}$ and least affected at $180^{\circ}$. With both -1 Dcyl \& -2 Dcyl binocular induced hypermetropic astigmatism, stereoacuity was affected maximum at $45^{\circ}$ and least affected at $180^{\circ}$. Stereoacuity in binocular induced hypermetropic astigmatism was more affected than binocular induced myopic astigmatism. Stereoauity was grossly affected in both monocular myopic and hypermetropic astigmatism. With the rule astigmatism had remarkable difference in stereoacuity in both myopic and hypermetropic induced astigmatism of 1 and 2 diopters cylinders. Stereoacuity was more affected in hypermetropic group. Conclusion: Stereoacuity is most affected at oblique axis $\left(45^{\circ}\right)$. There is gross reduction in stereoacuity in induced monocular astigmatism than binocular astigmatism. Both myopic and hypermetropic against the rule astigmatism has comparable deterioration of stereoacuity.
\end{abstract}

Keywords: Binocular astigmatism, Monocular astigmatism, Single Vision, Stereopsis

\section{Introduction}

Humans live in a three-dimensional world and the ability to perceive depth is, therefore, invaluable in everyday life. Precise judgments of depth are essential for daily activities. Indeed, a high grade of depth perception is a necessary requirement in many professions. This depth perception is termed as Stereopsis, a word derived from the Greek language

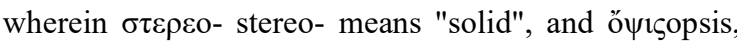
means "sight".

In ophthalmology, stereopsis is defined as the relative ordering of visual objects in depth, and represents the highest grade of binocular single vision, wherein two

Manuscript received: $28^{\text {th }}$ September 2019

Reviewed: $7^{\text {th }}$ October 2019

Author Corrected: $14^{\text {th }}$ October 2019

Accepted for Publication: $18^{\text {th }}$ October 2019 dissimilar images of the same object are formed simultaneously, on the retinae of the two eyes [1]. These images are then processed in the visual cortex to produce a single fused image, whose location in space can be perceived. Gross stereopsis for distant vision may be possible uniocularly, because of monocular cues like linear perspective, motion parallax, inter position, relative sizes of objects etc.

Stereopsis represents the highest grade of Binocular Single Vision wherein two dissimilar images of the same object are formed, simultaneously, at the maculae of the two eyes, and these images are then processed in the visual cortex to produce a single fused image, whose location in space can be perceived. Wheatstone proved that horizontal disparities of the images, rather than 
vertical disparities, were of greater relevance for the sensation of depth [1]. The minimal disparity detectable by an individual is termed as stereoacuity. Stereoacuity may be quantitatively assessed by means of a stereoscope. The first Stereoscope was invented by Wheatstone in 1838.

Stereoacuity is affected by various factors, such as misalignment of visual axes, refractive errors,

\section{Original Research Article}

anisometropia, and amblyopia. Astigmatism is an important factor, as its prevalence is fairly high, being between $6.33 \%$ [2] to $36.9 \%$ [3] in children. However, previous references in the literature contain little information regarding the relationship between stereoacuity and refractive errors, especially astigmatism $[4,5]$. This study was therefore conducted to determine the correlation between stereoacuity and induced astigmatism in emmetropes.

\section{Material and Methods}

Present Randomized, Prospective, Comparative, study was performed at Department of Ophthalmology Bharati Hospital \& Research Centre, Pune. Study Participants were recruited from individuals attending Bharati Hospital \& Research Centre, Pune and individuals from various school \& college screening programmes during the period August 2012 to August 2014.

\section{Inclusion criteria}

Individuals between 8-35 years. of age having Unaided Visual Acuity 6/6 in both eyes and with binocular single vision.

\section{Exclusion criteria}

Individuals having squint.

Individuals with already diagnosed amblyopia.

Individuals having any other ocular disease

Written informed consent for the study was obtained from all the participants prior to enrolment in the study. Demographic data and detailed history were captured on a predetermined proforma. Complete ocular examination in all participants was performed.

All individuals were tested on a contour-based test i.e. Titmus fly stereotest (range 20-400 seconds of arc) using Polaroid glasses. Final Sample Size calculated was 2000. They were divided into 2 groups using randomized table.

- Group 1 was subjected to binocular induced astigmatism.

- Group 2 was subjected to monocular induced astigmatism.

Group 1: (Binocular Induced Astigmatism): This group included 1000 individuals. They were again divided into 2 subgroups: - GROUP 1 (A): (Binocular Induced Myopic Astigmatism) This group included 500 individuals. First the baseline stereoacuity of all individuals was recorded. Then binocular myopic astigmatism was induced in each individual with +1.00 D cyl. \& +2.00 D cyl individually at $900,1800 \& 450 \&$ stereoacuity was recorded each time.

Group 1 (B): (Binocular Induced Hypermetropic Astigmatism) This group included 500 individuals. First the baseline stereoacuity of all individuals was recorded. Then binocular hypermetropic astigmatism was induced in each individual with -1.00 D cyl. \& -2.00 D cyl individually at $900,1800 \& 450 \&$ stereoacuity was recorded each time.

Group 2: (Monocular Induced Astigmatism) This group included 1000 individuals. They were again divided into 2 subgroups: GROUP 2 (A) :-( Monocular Induced Myopic Astigmatism)

This group included 500 individuals. First the baseline stereoacuity of all individuals was recorded. Then monocular myopic astigmatism was induced in each individual with +1.00 D cyl. \& +2.00 D cyl individually at $900,1800 \& 450 \&$ stereoacuity was recorded each time.

Group 2 (B): (monocular induced hypermetropic astigmatism) This group included 500 individuals. First the baseline stereoacuity of all individuals was recorded. Then monocular hypermetropic astigmatism was induced in each individual with -1.00 D cyl. \& -2.00 D cyl individually at 900, $1800 \& 450$ \& stereoacuity was recorded each time. 


\section{Original Research Article}

Statistical analysis: The recorded data was compiled and entered in a spreadsheet computer program (Microsoft Excel 2007) and then exported to data editor page of SPSS version 15 (SPSS Inc., Chicago, Illinois, USA).

Descriptive statistics included computation of percentages, means and standard deviations. For all tests, confidence level and level of significance were set at $95 \%$ and $5 \%$ respectively.

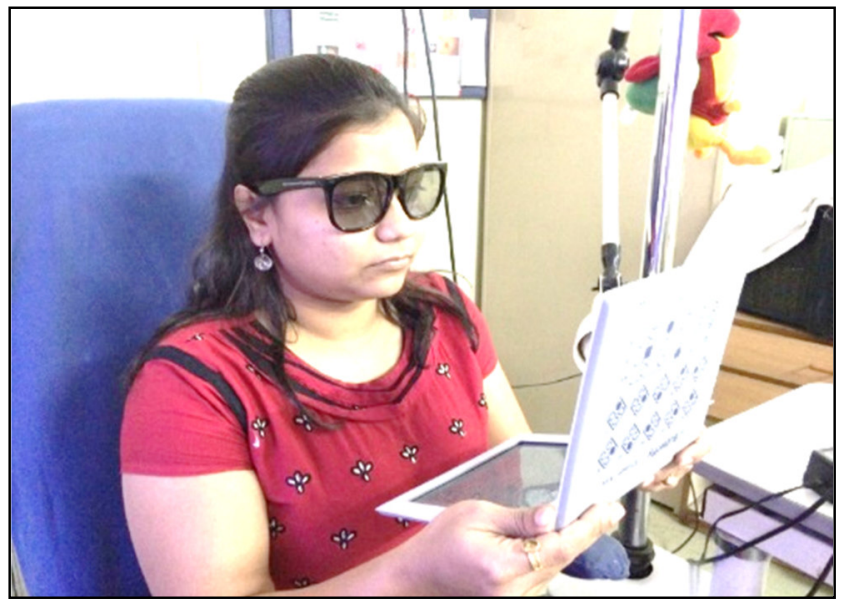

Fig 1: Baseline stereoacuity

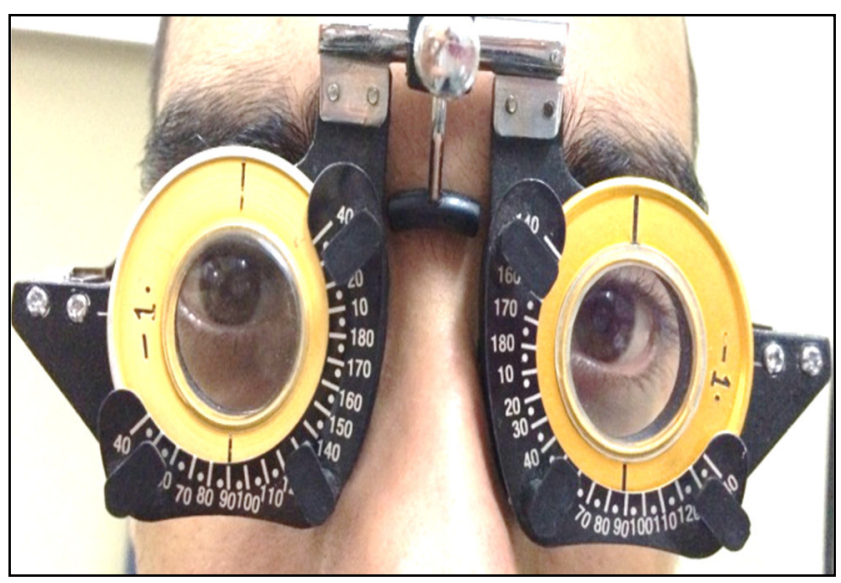

Fig 2: Binocular induced astigmatism

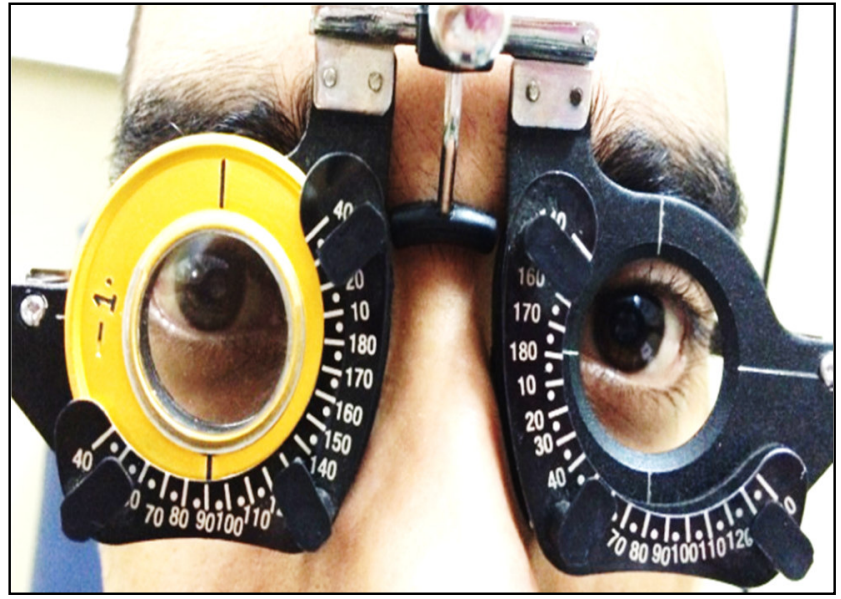

Fig 3: Uniocular induced astigmatism 


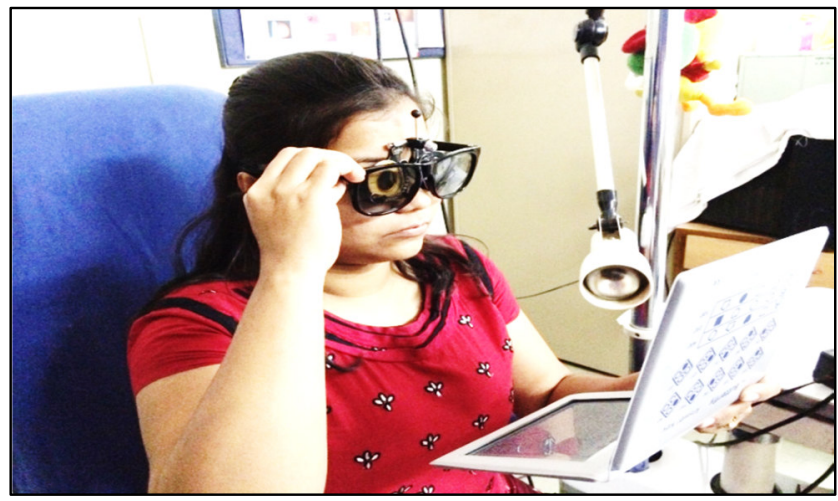

Fig 4: re-recording of stereoacuity

\section{Results}

The present study was conducted during the period of August 2012 to August 2014 at Ophthalmic OPD of a teaching hospital and various school and college screening programmes. There were total of 2000 participants from ages 8-35 years, mean age being 20.8 years. There were 1012 males and 988 females (Table 1). Mean baseline stereoacuity was $28.8 \pm 4.9$ second of arc (range 20-40 second of arc).

Table-1: Gender distribution.

\begin{tabular}{|c|c|c|}
\hline Gender & Number of patients & Percentage (\%) \\
\hline Male & 1012 & 49 \\
\hline Female & 988 & 51 \\
\hline Total & $\mathbf{2 0 0 0}$ & $\mathbf{1 0 0}$ \\
\hline
\end{tabular}

With both +1 Dcyl \& +2 Dcyl binocular induced myopic astigmatism, stereoacuity was affected maximum at $45^{\circ}$ and least affected at $180^{\circ}$ (Table 2).

Table-2: (Group 1-A) Binocular induced myopic astigmatism with +1.00 Dcyl \& +2.00 Dcyl.

\begin{tabular}{|c|c|c|c|}
\hline & $\begin{array}{c}\text { Mean stereoacuity in induced myopic } \\
\text { astigmatism with }+\mathbf{1 . 0 0} \text { Dcyl }\end{array}$ & $\begin{array}{c}\text { Mean stereoacuity in induced myopic } \\
\text { astigmatism with +2.00 Dcyl }\end{array}$ & p value \\
\hline $\begin{array}{c}\text { Baseline } \\
\text { (sec of arc) }\end{array}$ & $28.03 \pm 4.97$ & $28.03 \pm 4.97$ & \\
\hline $180^{0}$ & $32.42 \pm 4.98$ & $55.15 \pm 7.37$ & $<0.001$ \\
\hline $90^{0}$ & $36.21 \pm 17.28$ & $58.97 \pm 9.51$ & $<0.001$ \\
\hline $45^{0}$ & $44.12 \pm 23.64$ & $79.25 \pm 19.11$ & $<0.001$ \\
\hline
\end{tabular}

Values are Mean \pm SD of mean.

With both -1 Dcyl \& -2 Dcyl binocular induced hypermetropic astigmatism, stereoacuity was affected maximum at $45^{\circ}$ and least affected at $180^{\circ}$ (Table 3 ).

Table-3: (Group 1-B) Binocular induced hypermetropic astigmatism with -1.00 Dcyl \& -2.00 Dcyl.

\begin{tabular}{|c|c|c|c|}
\hline & $\begin{array}{c}\text { Mean stereoacuity in induced } \\
\text { hypermetropic astigmatism with } \\
\mathbf{- 1 . 0 0} \text { Dcyl }\end{array}$ & $\begin{array}{c}\text { Mean stereoacuity in induced } \\
\text { hypermetropic astigmatism } \\
\text { with -2.00 Dcyl }\end{array}$ & p value \\
\hline Baseline (sec of arc) & $28.76 \pm 4.97$ & $28.76 \pm 4.97$ & $<0.001$ \\
\hline $180^{0}$ & $38.51 \pm 8.50$ & $68.56 \pm 17.33$ & $<0.001$ \\
\hline $90^{0}$ & $43.41 \pm 8.97$ & $88.97 \pm 46.87$ & $<0.001$ \\
\hline $45^{0}$ & $52.34 \pm 9.19$ & $116.09 \pm 31.62$ & \\
\hline
\end{tabular}

Values are Mean \pm SD of mean. 
With both +1 Dcyl \& +2 Dcyl monocular induced myopic astigmatism, there was gross reduction in stereoacuity specially with +2 D cylinder (Table 4 ).

Table-4: (Group 2-A) Monocular Induced Myopic astigmatism with +1.00 Dcyl \& +2.00 Dcyl.

\begin{tabular}{|c|c|c|c|}
\hline & $\begin{array}{c}\text { Mean stereoacuity in induced } \\
\text { myopic astigmatism with } \\
+\mathbf{1 . 0 0} \text { Dcyl }\end{array}$ & $\begin{array}{c}\text { Mean stereoacuity in } \\
\text { induced myopic astigmatism } \\
\text { with }+\mathbf{2 . 0 0} \text { Dcyl }\end{array}$ & p value \\
\hline Baseline (sec of arc) & $29.45 \pm 5.07$ & $29.45 \pm 5.07$ & $<0.001$ \\
\hline $180^{\circ}$ & $55.90 \pm 7.47$ & $110.68 \pm 22.97$ & $<0.001$ \\
\hline $90^{\circ}$ & $58.74 \pm 7.32$ & $119.80 \pm 28.24$ & $<0.001$ \\
\hline $45^{\circ}$ & $76.49 \pm 18.61$ & $153.36 \pm 34.01$ & $<$ \\
\hline
\end{tabular}

Values are Mean $\pm \mathrm{SD}$ of mean.

With both -1 Dcyl \& -2 Dcyl monocular induced hypermetropic astigmatism, there was gross reduction in stereoacuity specially with -2 D cylinder (Table 5). Stereoacuity in binocular induced hypermetropic astigmatism was more affected than binocular induced myopic astigmatism (Table 6).

Table-5: (Group 2-B) Monocular induced hypermetropic astigmatism with -1.00 Dcyl \& $\mathbf{- 2 . 0 0}$ Dcyl.

\begin{tabular}{|c|c|c|c|}
\hline & $\begin{array}{c}\text { Mean stereoacuity in induced } \\
\text { hypermetropic astigmatism } \\
\text { with -1.00 Dcyl }\end{array}$ & $\begin{array}{c}\text { Mean stereoacuity in } \\
\text { induced hypermetropic } \\
\text { astigmatism with -2.00 Dcyl }\end{array}$ & p value \\
\hline Baseline (sec of arc) & $29.01 \pm 4.97$ & $29.01 \pm 4.97$ & \\
\hline $180^{0}$ & $56.94 \pm 6.49$ & $113.68 \pm 25.20$ & $<0.001$ \\
\hline $90^{0}$ & $61.19 \pm 11.30$ & $123.08 \pm 31.47$ & $<0.001$ \\
\hline $45^{\circ}$ & $80.50 \pm 18.74$ & $156.16 \pm 33.97$ & $<0.001$ \\
\hline
\end{tabular}

Values are Mean \pm SD of mean.

Table-6: Comparison between binocular myopia and binocular hypermetropia.

\begin{tabular}{|c|c|c|c|}
\hline & $\begin{array}{c}\text { Mean stereoacuity in binocular } \\
\text { induced myopic astigmatism }\end{array}$ & $\begin{array}{c}\text { Mean stereoacuity in binocular } \\
\text { induced hypermetropic astigmatism }\end{array}$ & p value \\
\hline Baseline & $\mathbf{+ 1 . 0 0}$ Dcyl & $\mathbf{- 1 ~ D ~ c y l}$ & 0.02 \\
\hline 180 & $28.03 \pm 4.97$ & $28.76 \pm 4.97$ & $<0.001$ \\
\hline 90 & $32.42 \pm 4.98$ & $38.51 \pm 8.50$ & $<0.001$ \\
\hline 45 & $36.21 \pm 17.28$ & $43.41 \pm 8.97$ & $<0.001$ \\
\hline Baseline & $44.12 \pm 23.64$ & $52.34 \pm 9.19$ & 0.02 \\
\hline 180 & $+\mathbf{2 . 0 0} \mathbf{D} \mathbf{~ c y l}$ & $\mathbf{- 2 ~ D ~ c y l}$ & $<0.001$ \\
\hline 90 & $28.03 \pm 4.97$ & $28.76 \pm 4.97$ & $<0.001$ \\
\hline 45 & $55.15 \pm 7.37$ & $68.56 \pm 17.33$ & $<0.001$ \\
\hline
\end{tabular}

Values are Mean \pm SD of mean.

Stereoauity was grossly affected in both monocular myopic and hypermetropic astigmatism (Table 7). 
Table-7: Comparison between monocular myopia and monocular hypermetropia.

\begin{tabular}{|c|c|c|c|}
\hline & $\begin{array}{c}\text { Mean stereoacuity in monocular } \\
\text { induced myopic astigmatism }\end{array}$ & $\begin{array}{c}\text { Mean stereoacuity in monocular } \\
\text { induced hypermetropic astigmatism }\end{array}$ & p value \\
\hline Baseline & $\mathbf{+ 1 . 0 0} \mathbf{D}$ cyl & $\mathbf{- 1 . 0 0} \mathbf{D}$ cyl & 0.159 \\
\hline 180 & $29.45 \pm 5.07$ & $29.01 \pm 4.97$ & 0.019 \\
\hline 90 & $55.90 \pm 7.47$ & $56.94 \pm 6.49$ & $<0.001$ \\
\hline 45 & $58.74 \pm 7.32$ & $61.19 \pm 11.30$ & 0.001 \\
\hline Baseline & $76.49 \pm 18.61$ & $80.50 \pm 18.74$ & 0.159 \\
\hline 180 & $\mathbf{+ 2 . 0 0} \mathbf{D}$ cyl & $\mathbf{- 2 . 0 0} \mathbf{D}$ cyl & 0.049 \\
\hline 90 & $29.45 \pm 5.07$ & $29.01 \pm 4.97$ & 0.083 \\
\hline 45 & $110.68 \pm 22.97$ & $113.68 \pm 25.20$ & 0.193 \\
\hline
\end{tabular}

With the rule astigmatism had remarkable difference in stereoacuity in both myopic and hypermetropic induced astigmatism of 1 and 2 diopters cylinders. Stereoacuity was more affected in hypermetropic group (Table 8).

Table-8: Comparison between with the rule (WTR) astigmatism and against the rule (ATR) astigmatism with the rule astigmatism.

\begin{tabular}{|c|c|c|}
\hline & Induced myopic astigmatism & Induced hypermetropic astigmatism \\
\hline Baseline stereoacuity & $28.03 \pm 4.97$ & $28.03 \pm 4.97$ \\
\hline With 1 D cylinder & $32.42 \pm 4.98$ & $43.41 \pm 8.97$ \\
\hline With 2 D cylinder & $55.15 \pm 7.37$ & $88.97 \pm 46.87$ \\
\hline
\end{tabular}

Table-9: Against the rule astigmatism.

\begin{tabular}{|c|c|c|}
\hline & Induced myopic astigmatism & Induced hypermetropic astigmatism \\
\hline Baseline stereoacuity & $28.03 \pm 4.97$ & $28.03 \pm 4.97$ \\
\hline With 1 D cylinder & $36.21 \pm 17.28$ & $38.51 \pm 8.50$ \\
\hline With 2 D cylinder & $58.97 \pm 9.51$ & $68.56 \pm 17.33$ \\
\hline
\end{tabular}

Against the rule astigmatism had comparable deterioration of stereoacuity in both myopic and hypermetropic induced astigmatism of 1 and 2 diopters cylinders (Table 9).

\section{Discussion}

Binocular depth perception or stereoacuity is usually fully developed by 6 years of age. Stereopsis requires normal functioning of both eyes and is adversely affected by rertacive errors, anisometropia, anisokonia and amblyopia. Stereopsis does not work beyond a critical distance which ranges between 125-200 meters. Beyond this distance the depth perception is possible because of monocular clues like motion parallax, linear perspective, overlay of contours, distribution of highlights and shadows, size of known objects and aerial perspective etc. depth perception by monocular clues is usually judgement based on previous experiences [1].

Tropical Journal of Ophthalmology and Otolaryngology
This study was conducted during the period August 2012 to August 2014 on a total of 2000 emmetropic individuals between the ages of 8-35 years (mean age was 20.8 years). They were randomly divided into 2 groups.

Group 1 was subjected to binocular induced astigmatism and group 2 was subjected to monocular induced astigmatism. Group 1 included 1000 individuals. They were again divided into 2 sub-groups of 500 each. Group 1 A -binocular induced myopic astigmatism) \& Group 1 B (binocular induced hypermetropic astigmatism). Similarly Group 2 
included 1000 individuals and they were again divided into $2 \mathrm{sub}$ - groups of 500 each, Group 2 A (monocular induced myopic astigmatism) \& Group 2 B (monocular induced hypermetropic astigmatism). This study included 1012 (51\%) males and 988 (49\%) females. All individuals were tested for near stereoacuity using Titmus Fly stereo test, which does not offer monocular clues and discourage guessing. Baseline stereoacuity was tested after complete ocular examination.

Graded myopic and hypermetropic astigmatism was induced at $90^{\circ}, 180^{\circ}$ and $45^{\circ}$ axes. Stereoacuity was rerecorded each time. Woods et al [5] have compared the distant and near stereoacuity in young adults with normal binocular vision and found no significant different between distance-habitual and near-habitual viewing. In the present study, stereoacuities in the emmetropes ranged from 20-40 second of arc, the mean baseline was $28.81 \pm 4.97$ seconds of arc. Under ideal experimental conditions stereoacuity thresholds may reach 2-3 seconds of arc [6,7] but in clinical practice, stereoacuity of 30-40 seconds is considered normal.

Heravian Shandiz J, et al in 2010 [4] reported mean stereopsis of $40.83 \pm 2.78$ seconds of arc with Titmus fly stereo test. The better acuities seen in the present study may be accounted for the fact that Heraviaan Shandiz J, et al used a titmus test which detected acuities only in the range of 40-800 seconds of arc [4].

Binocular myopic astigmatism was experimentally induced in 500 individuals by introducing $+1 \mathrm{D}$ cylinders and +2 D cylinders in front of the subjects' eyes at varying axes i.e. $45^{\circ}, 90^{\circ}$ and $180^{\circ}$. Other workers, Chen, et al have studies the effect of induced binocular myopic astigmatism using plain cylinders 8.75 D to 11.5 D and Shinichiro Nakano, et al [7] have used $+1.0,+2.0$ and $+3.0 \mathrm{D}$. Mean stereoacuity in this group was $28.03 \pm 4.97$ arc seconds. The mean stereoacuity was $32.42 \pm 4.97$ arc seconds $(\mathrm{P}<0.001)$ at $180^{\circ}, 36.21 \pm 17.28$ arc seconds $(\mathrm{P}<0.001)$ at $90{ }^{\circ}$ and maximum reduction to $44.12 \pm 23.64$ arc seconds $(\mathrm{P}<0.001)$ was noted at $45^{\circ}$ axis.

There was gross reduction of stereoacuity to $55.15 \pm 7.37$ $(\mathrm{P}<0.001)$ at $180^{\circ}, 58.97 \pm 9.51(\mathrm{P}<0.001)$ at $90^{\circ}$ and $79.25 \pm 19.11 \quad(\mathrm{P}<0.001)$ at $45^{0}$ axis. Binocular hypermetropic astigmatism was experimentally induced in 500 individuals by introducing $-1 \mathrm{D}$ cylinders and -2 $\mathrm{D}$ cylinders in front of the subjects' eyes at varying axes i.e. $45^{\circ}, 90^{\circ}$ and $180^{\circ}$. Mean stereoacuity in this group was $28.76 \pm 4.97$ arc seconds. With $-1 \mathrm{D}$ cyl the mean stereoacuity was $38.51 \pm 8.51$ arc seconds $(\mathrm{P}<0.001)$ at $180^{\circ}, 43.41 \pm 8.97$ arc seconds $(\mathrm{P}<0.001)$ at $90^{\circ}$ and

\section{Original Research Article}

maximum reduction to $52.34 \pm 9.19$ arc seconds (P $<0.001$ ) was noted at $45^{\circ}$ axes. With $-2 \mathrm{D}$ cyl there was gross reduction of stereoacuity to $68.56 \pm 17.33$ arc seconds $(\mathrm{P}<0.001)$ at $180^{\circ}, 88.97 \pm 46.87$ arc seconds $(\mathrm{P}<0.001)$ at $90^{\circ}$ and $116.09 \pm 31.62$ arc seconds $(\mathrm{P}<0.001)$ at $45^{\circ}$ axes. In groups, $1 \mathrm{~A}$ and $1 \mathrm{~B}$, the steroacuity was significantly affected. The deterioration was proportional to increase in diopters of astigmatism irrespective of myopic or hypermetropic astigmatism.

Maximum deterioration was noted at $45^{\circ}$ axes with both myopic and hypermetropic astigmatism and although significant, stereoacuity was least affected at $180^{\circ}$ in both the groups. Amongst the two groups stereoacuity was significantly affected in hypermetropic astigmatism as compared with respective myopic group. Astigmatism induces image blur which causes deterioration of stereoacuity. The image blur is proportional to the dioptric power of astigmatism and thus the stereoacuity deteriorates with increase in diopteric power of astigmatism irrespective of myopia or hypermetropia.

The findings in this group are consistent with the results seen by Chen, et al [8] reported the reduction in depth discrimination was dependent on the axis of the induced astigmatism $(\mathrm{p}<0.01)$. The maximum effect occurred with orthogonal-oblique orientations (x45 left; x135 right), followed by against-the-rule (ATR) astigmatism; with-the-rule (WTR) astigmatism had the least effect (p $<0.001)$. Shinichiro Nakano et al [7] also reported similar results.

Horizontal disparity is the basis of steropsis. The astigmatism at vertical axis $\left(90^{\circ}\right)$ increases the horizontal disparity causing greater reduction in stereopsis [9, 10]. The present study showed that there was minimal deterioration of stereoacuity at horizontal axis $\left(180^{\circ}\right)$ regardless of whether the astigmatism was myopic or hypermetropic, which indicated that vertical disparity affected depth discrimination to a lesser extent than horizontal disparity. Oblique astigmatism, affects both horizontal and vertical disparity, thus may account for the greater effect on stereoacuity.

Monocular myopic astigmatism was experimentally induced in 500 individuals by introducing $+1 \mathrm{D}$ cylinders and +2 D cylinders in front of the subjects' eyes at varying axes i.e. $45^{\circ}, 90^{\circ}$ and $180^{\circ}$. Mean stereoacuity in this group was $29.45 \pm 5.07$ arc seconds.

With +1 D cyl the mean stereoacuity was $55.90 \pm 7.47$ arc seconds $(\mathrm{P}<0.001)$ at $180^{\circ}, 58.74 \pm 7.32$ arc seconds $(\mathrm{P}<0.001)$ at $90^{0}$ and maximum reduction to 
$76.49 \pm 18.61$ arc seconds $(\mathrm{P}<0.001)$ was noted at $45^{0}$ axes. With $+2 \mathrm{D}$ cyl there was gross reduction of stereoacuity to $110.68(\mathrm{P}<0.001)$ at $180^{\circ}, 119.80$ $(\mathrm{P}<0.001)$ at $90^{\circ}$ and $153.36(\mathrm{P}<0.001)$ at $45^{\circ}$ axes.

Monocular hypermetropic astigmatism was experimentally induced in 500 individuals by introducing - $1 \mathrm{D}$ cylinders and -2 D cylinders in front of the subjects' eyes at varying axes i.e. $45^{\circ}, 90^{\circ}$ and $180^{\circ}$. Mean stereoacuity in this group was $29.01 \pm 4.97$ arc seconds. With -1 D cyl the mean stereoacuity was $56.94 \pm 6.49$ arc seconds $(\mathrm{P}<0.001)$ at $180^{\circ}, 61.19 \pm 11.30$ arc seconds $(\mathrm{P}<0.001)$ at $90^{\circ}$ and maximum reduction to $80.50 \pm 18.74$ arc seconds $(\mathrm{P}<0.001)$ was noted at $45^{0}$ axes. With $-2 \mathrm{D}$ cyl there was gross reduction of stereoacuity to $113.68 \pm 25.20$ arc seconds $(\mathrm{P}<0.001)$ at $180^{\circ}, 123.08 \pm 31.47$ arc seconds $(\mathrm{P}<0.001)$ at $90^{\circ}$ and $156.16 \pm 33.97$ arc seconds $(\mathrm{P}<0.001)$ at $45^{\circ}$ axes.

In both groups $2 \mathrm{~A}$ and $2 \mathrm{~B}$ the steroacuity was significantly affected. The deterioration was proportionate to increase in diopters of astigmatism irrespective of myopic or hypermetropic astigmatism.

Maximum deterioration was noted at $45^{\circ}$ axes with both myopic and hypermetropic astigmatism and although significant, stereoacuity was least affected at $180^{\circ}$ in both the groups. Amongst the two groups stereoacuity was significantly affected in hypermetropic astigmatism as compared with respective myopic group. In monocular astigmatism in addition to image blur caused by astigmatism, binocular disparity of retinal images also plays role in reduction of stereoacuity.

The findings in this group are consistent with the results seen by Ouguz et al [10] reported that stereoacuity levels were reduced in proportion to the degree of anisometropia. Three diopters of anisometropia, regardless of type, produced a marked reduction of stereoacuity in all patients. Similar results were found by Heravian $\mathbf{J}$ et al [4], they reported that there was significant reduction in stereopsis level with respect to the degree and types of meridional anisometropia $(\mathrm{p}<$ $0.001)$.

Maximum reduction of stereopsis occurred with $4 \mathrm{D}$ myopic and hypropic astigmatic anisometropia in oblique axis. It was $773.33 \pm 101 / 4$ and $693.33 \pm / 179.9$ second of arc for Titmusstereo test.

Comparison between mean stereopsis in myopic or hypropic astigmatic anisometropia was statistically significant in all three axes; horizontal, vertical and oblique $(\mathrm{p}<0.001)$.

\section{Original Research Article}

The comparison between monocular vs binocular induced astigmatism showed significant greater deterioration in monocular astigmatism than in binocular group. This again highlights the role of binocular retinal image disparity in stereopsis.

The results in this group are in consistent with the results seen by Shinichiro Nakano et al [7] who reported that stereopsis degraded in both binocular and monocular astigmatic induction as astigmatic power increased but there were no apparent differences in stereopsis between binocular and monocular astigmatic induction.

In the present study against the rule astigmatism had comparable deterioration of astigmatism in both myopic cylinder at $90^{\circ}$ and hypermetropic cylinder at $180^{\circ}$ of 1 and 2 diopters in both monocular and binocular groups. There was remarkable difference in with the rule astigmatism in myopic and hypermetropic group.

The mean strereoacuity in +1 D cyl induced astigmatism at $180^{0}$ was $32.42 \pm 4.98$ arc seconds, whereas with - $1 \mathrm{D}$ cyl at $90^{\circ}$ induced hypermeropic astigmatism stereoacuity deterorated to $43.41 \pm 8.97$ arc seconds.

Similarly, the mean stereoacuity in $+2 \mathrm{D}$ cyl induced astigmatism at $180^{\circ}$ was $55.15 \pm 7.37$ arc seconds whereas with $-2 \mathrm{D}$ cyl at $90^{\circ}$ induced hypermetropic astigmatism, stereoacuity deteriorated to $88.97 \pm 46.87$ arc seconds.

Stereoacuity is more affected by hypermetropic with the rule astigmatism compared to myopic with the rule astigmatism. Chen et al [8] reported that the effect of WTR astigmatism was lesser compared with ATR astigmatic blur on depth discrimination.

The study was conducted in emmetropic individuals with normal binocular function by experimentally inducing astigmatism. They were not adapted to the image blur and disparity. The effect on stereoacuity might be different in individuals who have astigmatism during critical period of binocular vision development

Limitation of the study were, it was conducted in emmetropic individuals with normal binocular function by experimentally inducing astigmatism.

They were not adapted to the image blur and disparity. The effect on stereoacuity might be different in individuals who have astigmatism during critical period of binocular vision development. 


\section{Conclusion}

There is proportionate decrease in stereo acuity with increase indioptric power of astigmatism. Hypermetropic astigmatism causes more deterioration in stereoacuity than myopic astigmatism. Stereoacuity is more affected at $90^{\circ}$ than at $180^{\circ}$ axis. Stereoacuity is most affected at oblique axis $\left(45^{\circ}\right)$.

There is gross reduction in stereoacuity in induced monocular astigmatism than binocular astigmatism.

Both myopic and hypermetropic against the rule astigmatism has comparable deterioration of stereoacuity. Stereoacuity is more affected by hypermetropic with the rule astigmatism compared to myopic with the rule astigmatism.

\section{What the study adds to the existing knowledge?}

This study suggests that even small degree of monocular or binocular astigmatism affects stereoacuity significantly. Therefore, should be corrected.

\section{Author's contribution}

Dr. Bhavna Dhanji Gagal: Formulated the aims \& objectives with study design and helped in data collection from medical record department.

Dr. Kavita Parekh: Contributed to the preparation of the manuscript and data analysis.

\section{Funding: Nil, Conflict of interest: Nil \\ Permission from IRB: Yes}

\section{References}

1. Elliott D. Clinical procedures in primary eye care. 3rd ed. Edinburgh: Elsevier/Butterworth Heinemann; 2007. p. 318.

2. Wen G, Tarczy-Hornoch K, McKean-Cowdin R, Cotter SA, Borchert M, Lin J, et al. Prevalence of myopia, hyperopia, and astigmatism in non-Hispanic white and Asian children: multi-ethnic pediatric eye disease study. Ophthalmol. 2013;120(10):2109-2116. doi: 10.1016/j.ophtha.2013.06.039. Epub 2013 Aug 14.

3. Kleinstein RN, Jones LA, Hullett S, Kwon S, Lee RJ, Friedman NE, et al. Refractive error and ethnicity in children. Arch Ophthalmol. 2003;121(8):1141-1147. doi: 10.1001/archopht.121.8.1141.

4. Heravian J, Azimi A, Mohammadpour M, Ostadimoghaddam H, Yekta A, Esmaily H. The effect of unilateral induced astigmatism on stereopsis. Med J Mash Univ Med Sci. 2010;53(2):90-97.

5. Wong BPH, Msc O, Woods RL, Mcoptom,, PELI E, OD M, FAAO. New England College of Optometry, Boston, Massachusetts (BPHW, EP), The Schepens Eye Research Institute and Harvard Medical School, Boston, Massachusetts (RLW, EP).

6. Westheimer G. The Ferrier Lecture, 1992. Seeing depth with two eyes: stereopsis. Proc Biol Sci. 1994;257(1349):205-214. doi: 10. 1098/rspb.1994. 0117.

7. Nakano S, Hiraoka T, Hasegawa Y, Oshika T. Effect of Monocularly And Binocularly Induced Astigmatic Blur On Stereopsis. Invest Ophthalmo Vis Sci. 2012;53:1778.

8. Chen SI, Hove M, McCloskey CL, Kaye SB. The Effect of Monocularly and Binocularly Induced Astigmatic Blur on Depth Discrimination Is Orientation Dependent. Optom Vision Sci. 2012;82(2):101-113. doi: 10.1097/01.OPX.0000153251.39450.B4.

9. Jethani J, Shah K, Kellaiya A, Patel N. The effect of experimentally induced anisometropia on binocularity and bifoveal fixation. GMJ. 2015;70(1):52-58.

10. Oguz H, Oguz V. The effects of experimentally induced anisometropia on stereopsis. J Pediatr Ophthalmol Strabismus. 2000;37(4):214-218.

\section{How to cite this article?}

Gagal B. D, Parekh K. Correlation between stereoacuity and induced astigmatism: a prospective study. Trop J Ophthalmol Otolaryngol.2019; 4(6):365-373. doi:10.17511/jooo.2019.i06.03 